\title{
Coordination Mechanisms for the Two-Echelon Newsvendor Model with Rapidly Responsive and Strategic Consumers
}

\author{
Dai Dai, ${ }^{1}$ Xinyu Gou, ${ }^{2}$ and Qiang Wei $\mathbb{D}^{3}$ \\ ${ }^{1}$ School of Economic Mathematics, Southwestern University of Finance and Economics, Chengdu 611130, China \\ ${ }^{2}$ School of Business Administration, Southwestern University of Finance and Economics, Chengdu 611130, China \\ ${ }^{3}$ School of Management and Economics, University of Electronic Science and Technology of China, Chengdu 611731, China
}

Correspondence should be addressed to Qiang Wei; wq_research@126.com

Received 16 January 2021; Revised 4 March 2021; Accepted 18 April 2021; Published 27 April 2021

Academic Editor: Wei Zhang

Copyright ( $) 2021$ Dai Dai et al. This is an open access article distributed under the Creative Commons Attribution License, which permits unrestricted use, distribution, and reproduction in any medium, provided the original work is properly cited.

\begin{abstract}
Aiming at the two-echelon newsvendor problem in which the market demand of commodities is random both in normal sales period and in liquidation period, this paper studies the pricing and ordering decision of retailers by using rational expectation equilibrium under the condition of considering consumers' strategic behavior and rapid response mechanism. Then, the decisionmaking problem under retailers' initial order quantity commitment is discussed, as well as the effect of commitment mechanism on supply chain performance. On this basis, both the two-part pricing contract and revenue-sharing contract are introduced to achieve supply chain coordination aiming at the profit maximization under the initial order quantity commitment mechanism. The results show that the rapid response mechanism can reduce the negative impact of consumers' strategic behavior, and the initial order quantity commitment can further reduce the impact and improve the retailers' profit. Both the two-part pricing contract and revenue-sharing contract can coordinate the whole supply chain in which the two-part pricing contract can distribute profit arbitrarily between manufacturers and retailers while the revenue-sharing contract can share risks among members of the supply chain.
\end{abstract}

\section{Introduction}

Newsvendor model is the basic model of stochastic storage theory, and it mainly discusses the retailers' decision-making problem under uncertain demand. The newsvendor model has always been a hotspot in operations management research. A large number of researchers have made in-depth discussions on pricing and ordering under uncertain conditions and expanded the classical newsvendor model from many aspects. At present, most of the studies on newsvendor problem are single-echelon; that is, the market demand of commodities in normal sales stage is random. After the end of the sales stage, all the remaining commodities (if any) can be sold in full clearance with residual value. It is more reasonable to assume that the decision-making procedure is a two-echelon newsvendor model with random market demand of commodities both in normal sales period and in liquidation period. Since the classical newsvendor model can be regarded as a special case of the two-echelon newsvendor model, it is more general to study the two-echelon stochastic demand.

In traditional supply chain management research, consumers' behavioral characteristics are often ignored. These documents assume that customers are passive participants who do not participate in supply chain decisions, as long as the consumer's reserved value of the product is not lower than the current retail price of the product, consumers will immediately buy goods. However, due to fierce market competition, discounted sales have become a commonly used promotional method. Faced with wave after wave of price reductions, consumers gradually learned to wait for the best buying opportunity. This rational behavior of consumers is called strategic customer in marketing. In this case, consumers are no longer passive recipients of prices, and strategic consumers will compare the consumer surpluses that they can obtain when manufacturers implement 
different price stages, thereby deciding when to buy. Current research has found that consumer's strategic behavior will have a great impact on supply chain members' decisions and supply chain performance. Ignoring consumer's strategic behavior may cause huge losses to decision makers. For example, Coase, the Nobel Prize winner in economics, found in his classic 1972 literature that in the face of consumers' waiting behavior, monopolistic retailers only set their retail prices as marginal production costs so that retailers can only obtain Zero profit; Anthes [1] research shows that if $10 \%$ of passengers believe that future ticket sales will reduce prices and choose to postpone the purchase, then airlines will lose at least $1 \%$ of their profits. Therefore, it is necessary to incorporate consumer's strategic behavior into our research.

Since the production of goods requires a certain lead time, retailers basically need to order in advance. In this case, it is often difficult to accurately match the order quantity and the demand quantity, which can easily cause insufficient supply or waste. Make-to-order is the most effective way to solve the above problems. Companies such as Toyota use order-oriented inventory strategies to significantly increase their own profits and reduce their risks. However, for seasonal commodities such as clothing and food, due to the low value of these commodities and the short sales cycle, the average consumer will not book such commodities. In this case, a quick response strategy will be an effective response. The rapid response system of the famous Spanish clothing brand ZARA should be a classic case in operation management. The company has an efficient supply chain system to ensure that it is the only fashion company in the world that can distribute the produced clothing to more than 850 specialty stores worldwide in 15 days. The rapid response mechanism effectively solves the balance between inventory and demand and is a green and sustainable operation improvement strategy $[2,3]$. At the same time, because the retailer has maintained a low inventory level, it also gives consumers the expectation that it is difficult to reduce prices in the future, so it is a common mean to respond to the strategic consumers.

In the decentralized supply chain, "double marginalization" is universal. In order to avoid its adverse effects, it is an important part of the research in the supply chain management to increase the overall profit of the supply chain and realize the Pareto improvement of the profit of each member. Constraining the decision of each member in the supply chain and realizing supply chain coordination through the supply chain contract is an effective method. Under the traditional supply chain, the centralized supply chain is usually the most profitable situation, and this profit level is the goal of supply chain coordination. However, due to the influence of consumers' strategic behaviors, the profit level under centralized conditions is not necessarily the most profitable. Therefore, it is necessary to find a higher level of overall supply chain profit as the goal of supply chain coordination and to introduce a reasonable coordination contract to realize supply chain coordination, and at the same time, according to the needs of practical applications, rationally profits are distributed and risks are shared among supply chain members.
Based on the above reasons, this paper studies a twostage supply chain system consisting of a manufacturer and a retailer. When the retailer is faced with two-echelon uncertain demand, considering the strategic behavior of consumers, the rapid response mechanism is introduced. The following three issues are discussed:

(1) In a centralized supply chain system, when consumers have strategic behavior, the equilibrium initial output of the supply chain and the retail price of goods in the first echelon are determined.

(2) How to cope with consumers' strategic behavior and improve the overall performance of supply chain through rapid response and initial order commitment mechanism of retailers.

(3) Because the retailer's one-sided initial order commitment is not credible, how to solve the problem of unreliable commitment, then achieve the maximum performance of the supply chain as a whole, and allocate profits and risk among the members of the supply chain.

The remaining parts of this paper are organized as follows. Section 2 gives a literature review; Section 3 is the basic setting of the model; Section 4 discusses the pricing and ordering decision-making of supply chain under centralized circumstances; Section 5 studies the role of retailer's initial order commitment; Section 6 introduces two-part pricing contracts and revenue-sharing contracts to coordinate the supply chain; Section 7 is the numerical experiment; and Section 8 gives the conclusion. The prospects of research are discussed.

\section{Literature Review}

The newsvendor model is the basic model of stochastic storage theory. It mainly discusses the decision-making problem of retailers under uncertain demand. Under the assumption that the market demand of commodities is random and the retail price is exogenous, the classical newsvendor model studies the retailer's decision-making method to maximize the expected profit. The newsvendor model has been the focus of operation management research since it has been put forward. A large number of researchers have conducted in-depth discussions on newsvendor and expanded the newsvendor model from many directions. For example, Petruzzi and Dada [4], Agrawal and Seshadri [5], and Dana and Petruzzi [6] have studied the joint decisionmaking problem of inventory and retail price under the condition of random market demand and price sensitivity. Kyparisis and Koulamas [7] discussed the optimal decisionmaking of retailers under the condition of nonlinear price sensitivity plus a stochastic variable demand function. Khouja [8] introduced multiple discount strategy to improve the sales volume and optimize the profit of retailers by continuously reducing the retail price of goods in the sales echelon. Ma et al. [9] extended the demand distribution from uniform distribution and normal distribution to arbitrary distribution on the basis of Khouja and studied the 
situation of reducing discount price according to nonlinearity. Cachon and Kok [10] regarded the residual value of goods after the normal selling period as the decision variable of the retailer and discussed the joint decision of the retailer's inventory and residual value under the setting of the newsvendor model. Based on the classical newsvendor model, the uncertainty of commodity supply is considered by Tang et al. [11]. Alfares and Elmorra [12] and Raza [13] analyzed the expectation and variance of commodity demand, while the distribution function was unknown. As a generalization, Adhikary et al. [14] studied the free distribution newsvendor model when the demand was a fuzzy random variable.

At present, most of the studies assume that the market demand of commodities in the normal sales stage is random. After the end of the sales echelon, all the remaining commodities (if any) can be sold in full clearance with residual value. The residual value set in the model is often less than the production cost, and the promotion is very strong, so this assumption has certain rationality. A more reasonable assumption is that the demand for goods is a random variable in multiple sales stages. Lee et al. [15] assumed that the market demand of commodities is divided into two stages [16] and that the market demand of each stage is a random variable, and the optimal ordering strategies of retailers are studied for retailers with only one order opportunity and two orders opportunity. Linh and Hong [17] and Hematyar and Chaharsooghi [18] aimed at a two-echelon supply chain system consisting of a single manufacturer and a single retailer. When retailers are faced with stochastic demand in both sales stages, the pricing and ordering of supply chain members and channel coordination are studied. Our model follows the assumption of two-echelon uncertain demand. The biggest difference from the above research is that we consider the strategic behavior of consumers.

The research on consumer strategic behavior is also closely related to this paper. Coase's [19] classical literature first focuses on the impact of consumer strategic behavior on retailer's pricing and performance. It is found that in the face of consumers' waiting behavior, monopoly retailers only set their retail price as marginal production cost so that retailers can only get zero profit. On the basis of Coase [19], a large number of subsequent literatures have studied the optimal decision-making problem based on consumer strategic behavior under different conditions. Mersereau and Zhang [20], Liu and Cooper [21], and Yan and Ke [22] have studied dynamic pricing strategies based on strategic consumers. Cachon and Swinney [23], Yin et al. [24], and so on took inventory as decision variable and discussed the ordering strategy based on strategic consumers. There are also some studies that regard retail price and order volume as decision variables, such as Lai et al. [25] assuming that both strategic and myopic consumers exist in the market, focusing on the pricing and inventory strategy formulation of retailers after introducing the final price matching strategy (PM). Dong and $\mathrm{Wu}$ [26] expanded to two stages of joint inventory and retail price decision-making. Su and Zhang [27] firstly considered the strategic behavior of consumers in the twoechelon supply chain system, which was composed by introducing manufacturers. The subsequent literature has been expanded on the basis of Su and Zhang's research. Yang [28] studied the two-stage pricing and ordering problem in a supply chain system consisting of a manufacturer and competing retailers, taking into account the strategic behavior of consumers. Li and Wang introduced repurchase contracts to discuss supply chain coordination for different types of strategic consumers. Ahmadi et al. [29] studied the decision-making of supply chain members in the face of grey market and strategic consumers and introduced wholesale price contracts and quantities to coordinate the supply chain. Hu et al. [30] analyzed the optimal prices and trade-in rebates for successive-generation products with strategic consumers and limited trade-in duration. Che et al. [31] studied the pricing decisions of retailers facing strategic consumers with low-carbon preferences in two situations based on a two-stage pricing model.

Related to this study is the literature on rapid response and supply chain coordination. Fisher and Raman [32] studied the role of rapid response mechanism in responding to demand uncertainty. Iyer and Bergen [33] introduced rapid response mechanism in supply chain channel selection and coordination. After introducing rapid response mechanism, the decision-making of manufacturers and retailers was analyzed by model analysis. Choi et al. [34] studied the effect of rapid response on supply chain when retailers' risk preferences were random. In the study by Chan et al. [35], considering the reduction of production lead time, greenhouse gas emissions and energy waste may become more serious, and a two-stage rapid response supply chain system with clean technology was proposed. Xu et al. [36] explored the effect of consumer disappointment aversion on the online seller's decisions about pricing, ordering, and quick response. In addition, some studies combine the quick response mechanism with the consumer's strategic behavior. Cachon and Swinney [23] studied the two-stage pricing and inventory strategy formulation of retailers under the assumption that there are both myopic customers, discountonly customers, and strategic customers in the market. Swinney [37] studied retailers' decision-making when facing both strategic and myopic consumers under the condition of second order and analyzed the effect of rapid response mechanism. Dong and Wu [26] studied two-echelon dynamic pricing and ordering strategies with strategic consumers and rapid response mechanism. Similar to our study are the studies of Yang et al. [22] and Wang et al. [2]. Yang et al. [22] analyzed the role of rapid response systems in responding to consumer strategic behaviors in four different supply chain structures, and Wang et al. [2] introduced rapid response mechanisms to study pricing and ordering issues under coexistence conditions of both the strategic and myopic consumers. However, they are all carried out under the framework of the classic newsvendor model. Yang et al. [22] did not realize the distribution of profits and risks when discussing supply chain coordination, while Wang et al. [2] did not involve supply chain coordination.

Two-part pricing is a common way of charging in economics. Similar to fixed cost and variable cost in cost theory, the seller divides the cost into two parts when selling 
goods: the first part is a fixed cost and the second part is the unit price of goods, through which complete price discrimination can be realized. Io [38] first proposed two-part pricing theory, and subsequent researchers introduced the theory into supply chain management, forming two-part pricing contract. Under the condition that retailers are dominant, the market demand of goods is sensitive to retail price, and the retail price is random, and the coordination of supply chain with two-part pricing contracts is studied by Lau et al. [39]. Wang et al. [40] extended the basis of Lau et al. [39]. Based on discussion of two-part pricing contract, a new batch discount contract was established to achieve supply chain coordination. The research and application of revenue-sharing contract are very extensive. The most classical literature is Cachon and Lariviere [41]. This paper introduces the theory of revenuesharing contract in detail, compares it with other supply chain coordination contracts, and discusses the advantages and limitations of revenue-sharing contract. Some scholars study supply chain coordination based on multiple contracts. For example, Saha [42] considered the impact of manufacturers' efforts on commodity demand, combined revenue sharing and rebates as tools for supply chain coordination, and proposed three different types of rebate inducement contract. Saha and Goyal [43] studied the ordering and pricing decision-making problems in a two-echelon supply chain in which the demand depends on the inventory level and sales price of the product. They realize supply chain coordination through a combination contract of the rebate contracts, wholesale price discount contracts, and cost sharing contracts; different coordination contracts have their own advantages and disadvantages, which is convenient for managers to make reasonable choices according to actual needs. Based on this, this article will also introduce different contracts to the supply chain coordination.

At present, most of the literatures that have been studied under framework of the newsvendor model are based on the single-period newsvendor model, and only a few literatures involved the two-stage newsvendor model. As far as the author knows, there is no research on the decision-making and coordination of the supply chain based on the two-stage newsvendor problem taking into account both the consumers' strategic behaviors and a quick response mechanism. Compared with the current literatures, our research has three main differences: firstly, under the basic setting of two-stage uncertain demand for the two-echelon supply chain system for the first time, the strategic behavior and rapid response mechanism of consumers are comprehensively considered (from the current literatures). Secondly, because of the existence of strategic consumers, the profit of supply chain under centralized conditions is not necessarily the same. We introduce the retail price commitment mechanism to improve the overall performance of the supply chain and find the goal of supply chain coordination. Thirdly, we use different coordination mechanisms to achieve the supply chain coordination so that profits and risks could be allocated in different ways among the supply chain members.

\section{The Basic Model}

This paper considers a two-echelon supply chain system consisting of a single manufacturer and retailer and a large number of consumers with strategic behaviors. The supply chain structure is shown in Figure 1. The notations used in this paper are shown in Table 1, and any other additional notations and assumptions will be listed where they are needed.

Similar to the sales process set by Lee et al. [15], the sales process of goods is divided into two stages. The first stage is the normal sales period, and the retailer will sell the goods at the retail price $p$. The second stage is the discount sales period. In this stage, the retailer will sell the goods at the retail price $h(h<p)$ and $h$ is an exogenous variable. At the end of the second stage, the retailer no longer clears the goods but returns the surplus goods to the manufacturer or sells them to the scrap collector. Each unit of the goods receives the residual value $s$.

It is assumed that the market demand faced by retailers in each stage is random variable $X_{i}, i=1,2$ where $X_{i}$ is independent of each other. $F_{i}(x)$ and $f_{i}(x)$ represent the distribution function and distribution density function of the random variable, respectively. Assume that $X_{i}$ is a continuous random variable and satisfies $X_{i}>0$. Then, $X=$ $X_{1}+X_{2}$ denotes the total market demand of two echelons, and $F(x)$ and $f(x)$ denote the distribution function and density function of $X$, respectively. In addition, the requirements of the first stage are required to meet the increasing failure rate (IFR), i.e., $f_{1}(x) /\left(1-F_{1}(x)\right)$ on the monotonic increment of $x$. Petruzzi and Dada [4], Su and Zhang [27], and Yang et al. [22] have used this hypothesis for many commonly used distributions, such as uniform distribution and normal distribution.

Assuming that the retailer has two order opportunities before the beginning of the first phase of the sales period, the first order is placed with the manufacturer at the wholesale price $c_{1}$. Then, the actual demand information in the first phase is learned (that is, as the sales season approaching, obtaining an accurate estimate for the actual value of the random variable $X_{1}$ ), and the retailer can place an order from the manufacturer again at the wholesale price $c_{2}$. The retailer needs to decide the initial order quantity $Q$ and the retail price $p$ during the first period of sale to maximize its own profit. For the manufacturer's second production, since the production preparation period is short and the output is generally small, it is reasonable to set the unit production cost to rise, so $c_{1}<c_{2}$. In order to ensure that the retailer does not only place a second order and that the second order can only be used to satisfy the first order is insufficient in the first stage of sales, assume $s<h<c_{1}<c_{2}$. As a result, the whole sales operation process is shown in Figure 2.

Assuming that in the first stage there are many homogeneous consumers in the market, their evaluation of the goods isv. And they all have strategic behavior; that is, consumers know that after the end of the first stage of sales period, if there are still goods not sold out, retailers will discount sales in the second stage. Consumers will maximize their expected utility as the goal to make the optimal 


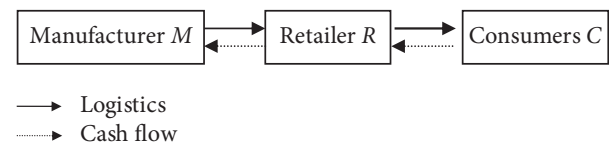

FiguRE 1: Supply chain structure.

TABle 1: Notations.

\begin{tabular}{|c|c|}
\hline Notation & Description \\
\hline \multicolumn{2}{|c|}{ Parameters } \\
\hline$h$ & Retail price in the second stage \\
\hline$X_{i}$ & The demand for product in the $i$ stage, $i=1,2$ \\
\hline$F_{i}(x)$ & Distribution function of random variable $X_{i}$ \\
\hline$f_{i}(x)$ & Distribution density function of random variable $X_{i}$ \\
\hline$c_{1}$ & $\begin{array}{l}\text { Unit production cost of the product when the first } \\
\text { order is placed }\end{array}$ \\
\hline$c_{2}$ & $\begin{array}{c}\text { Unit production cost of the product when the second } \\
\text { order is placed }\end{array}$ \\
\hline$S$ & $\begin{array}{c}\text { Unit residual value of remaining product after the sales } \\
\text { period }\end{array}$ \\
\hline$v$ & $\begin{array}{c}\text { Consumers' valuation of product during normal sales } \\
\text { period }\end{array}$ \\
\hline$r$ & $\begin{array}{c}\text { Consumers' reservation price for product during } \\
\text { normal sales period }\end{array}$ \\
\hline \multicolumn{2}{|c|}{ Decision variables } \\
\hline$p$ & Retail price in the first \\
\hline$Q$ & Retailer's initial order quantity \\
\hline
\end{tabular}

purchase timing. In the second stage, consumers have no more choices, which is consistent with the classical newsvendor model. Under the exogenous retail price $h$, they decide whether to buy goods or not.

Assuming that the manufacturer's production capacity is infinite, it can fully satisfy the retailer's initial and second orders; the members of the supply chain are risk-neutral, and the consumer's valuation of the goods in the first stage does not change with time, that is, the same in both sales stages, and the time value of the funds is not taken into account. Events occur in the following order.

Firstly, retailers estimate the retail price $r$ of consumers in the first stage $\xi_{r}$ and then determine the optimal retail price $p$ and the initial order quantity $Q$. At the same time, consumers estimate $Q$ and obtain the probability $\xi_{\text {prob }}$ that they can buy goods in the discount sales period so as to determine the retail price $r$.

Next, the actual selection of the random variable $X_{1}$ is worth it. If $Q<X_{1}$, the retailer will place a second order at the price of $c_{2}$ to meet the market demand in the first stage and then sell all the goods at the retail price $p$ in the first stage of the sales period; otherwise, without a second order, the retailer will continue to sell the goods at the retail price $h$ after the first stage of the sales period, and if there are surplus goods after the second stage of the sales period, all remaining goods will be disposed of with residual $s$.

\section{Centralized Supply Chain}

Firstly, the pricing and ordering decisions of retailers in centralized supply chain are discussed. In the setting of centralized supply chain, manufacturers and retailers as a whole are collectively referred to as retailers in order to express conveniently.

According to the sequence of events mentioned above, the consumer's decision-making in the first stage is analyzed. Before the first stage of sales, the retailer will announce the retail price $p$ of the first stage, and the initial order quantity is the retailer's private information. Therefore, consumers need to estimate $Q$, which is to estimate the probability $\xi_{\text {prob }}$ that the goods can be bought at the price $h$ after the end of the first stage of sales. Then, with the goal of maximizing utility, the purchase timing is decided, namely:

$$
\max \left\{v-p,(v-h) \xi_{\text {prob }}\right\} .
$$

The first term $v-p$ in the above expression represents the consumer surplus obtained by purchasing goods in the first stage, and the second term $(v-h) \xi_{\text {prob }}$ represents the expected surplus obtained by purchasing goods at the end of the season. So, if and only if $v-p \geq(v-h) \xi_{\text {prob }}$, the retail price of the commodity is $p \leq v-(v-h) \xi_{\text {prob }}$, and the strategic consumer will choose to buy the commodity in the first stage. Therefore, in the first stage, consumers retain the price of goods as $r=v-(v-h) \xi_{\text {prob }}$.

The retailer's decision-making is analyzed below. Because the retailer's reserved price is also the consumer's private information, the retailer needs to estimate it, assuming that $\xi_{r}$ represents the estimation of the consumer's reserved price. Obviously, in order to maximize profits, the retailer's retail price in the first stage should be fixed $p=\xi_{r}$. Initial order quantity $Q=\arg \max \pi(p, Q)$, in which

$$
\begin{aligned}
\pi(p, Q)= & p E\left(X_{1} \wedge Q\right)+\left(p-c_{2}\right) E\left(X_{1}-Q\right)^{+}+h E \\
& \cdot\left[\left(Q-X_{1}\right)^{+} \wedge X_{2}\right]+s E\left[\left(Q-X_{1}\right)^{+}-X_{2}\right]^{+}-c_{1} Q .
\end{aligned}
$$

In this paper, we use " $\wedge$ " to denote the small between them and " $V$ " to denote the large, for example $(X-Q)^{+}=$ $(X-Q) \vee 0$. In formula $(2), p E\left(X_{1} \wedge Q\right)$ is the profit obtained by selling goods at retail price $p$ in the first stage, $(p-$ $\left.c_{2}\right) E\left(X_{1}-Q\right)^{+}$is the expected profit from the second order when the initial order quantity is insufficient, $h E\left[\left(Q-X_{1}\right)^{+} \wedge X_{2}\right]$ expresses the profit obtained by selling goods at retail price $h$ in the second stage, the residual value $s E\left[\left(Q-X_{1}\right)^{+}-X_{2}\right]^{+}$denotes the income of goods obtained by the retailer after the second stage of sale, and $c_{1} Q$ expresses the initial order cost.

In determining the value of $\xi_{\text {prob }}$ and $\xi_{r}$, this paper uses the rational expectation hypothesis. Rational expectation is put forward by Muth [44]. The so-called rational expectation is that every economic actor's expectation of future events is rational; that is, consumers use their own maximum effectiveness as the criterion of action, producers take profit maximization as the criterion of action, and any economic actor's anticipated future situation when making current decisions is always completely accurate. It is in line with the actual situation in the future. Thus, the following definitions can be obtained. 


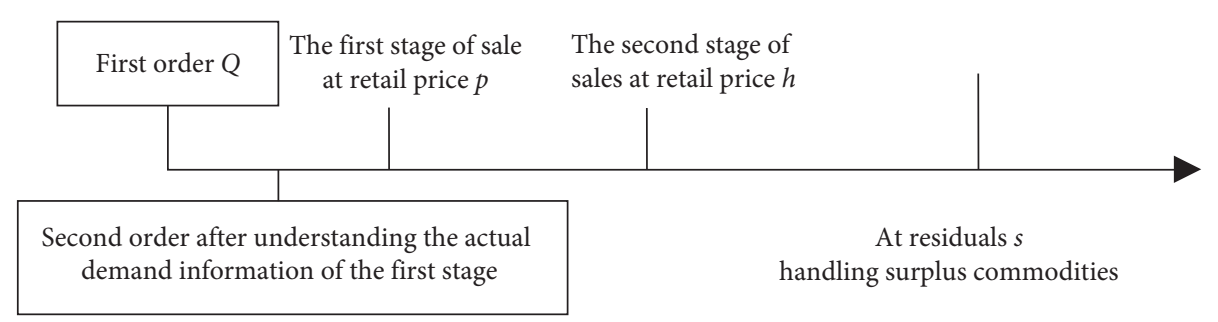

Figure 2: Diagram of operation process.

Definition 1. In the two-echelon newsvendor model based on consumer strategic behavior under the rapid response mechanism, a rational expectation equilibrium $\left(p, Q, \xi_{\text {prob }} \xi_{r}\right)$ should satisfy the following five conditions:
(i) $r=v-(v-h) \xi_{\text {prob }}$
(ii) $p=\xi_{r}$
(iii) $Q=\arg \max \pi(p, Q)$
(iv) $\xi_{\text {prob }}=F_{1}(Q)$
(v) $\xi_{r}=r$

Conditions (i), (ii), and (iii) indicate that retailers and consumers should make rational decisions; that is, consumers should maximize consumer surplus and retailers should maximize expected profits; conditions (iv) and (v) indicate that consumers and retailers' estimates of private information are consistent with the actual situation, which is the core of rational expectations.

According to Definition 1, we can get two conditions that the retailer's decision variables should satisfy under the condition of rational expectation equilibrium (introducing subscript $c$ to represent rational expectation equilibrium state, that is, the case of centralized supply chain):

$$
p_{c}=v-(v-h) F_{1}(Q), Q_{c}=\arg \max \pi(p, Q) .
$$

Proposition 1. In the equilibrium of rational expectations, consumers in the first stage will buy goods in the first stage, and there exists only $p_{c}$ and $Q_{c}$ to maximize the profit of retailers.

Proof. The expected profit of the retailer obtained by formula (2) is as follows:

$$
\begin{aligned}
\pi(p, Q)= & \left(p-c_{2}\right) E\left(X_{1}\right)+\left(c_{2}-c_{1}\right) Q-\left(c_{2}-h\right) \\
& \cdot \int_{0}^{Q} F_{1}(x) \mathrm{d} x-(h-s) \int_{0}^{Q} F(x) \mathrm{d} x .
\end{aligned}
$$

Therefore, the first-order condition is as follows:

$$
\frac{\partial \pi}{\partial Q}=\left(c_{2}-c_{1}\right)-\left(c_{2}-h\right) F_{1}(Q)-(h-s) F(Q)=0 \text {. }
$$

Let $g(Q)=\left(c_{2}-c_{1}\right)-\left(c_{2}-h\right) F_{1}(Q)-(h-s) F(Q)$, then the function $g(Q)$ monotonously decreases on $Q$ in the interval $[0+\infty)$, and because $g(0)=\left(c_{2}-c_{1}\right)>0, g(\infty)=$ $\left(s-c_{1}\right)<0$; therefore, the profit function has a unique stationary point $Q_{c}$. According to the second-order condition $\partial^{2} \pi / \partial Q^{2}=-\left(c_{2}-h\right) f_{1}(Q)-(h-s) f(Q)<0$, the only stationary point is the maximum point. From formula (3), we can see that the retail prices $p_{c}$ and $Q_{c}$ are one-to-one correspondence under the equilibrium condition, so $p_{c}$ is the only one that exists. Proof is completed.

Proposition 2. This guarantees the unique existence of equilibrium solution under the assumption of rational expectation. $Q_{c}$ is the solution of equation $g(Q)=0$. However, when the random variable $X_{i}$ is normal or Poisson's distribution, it will be very difficult to solve the analytical expression of $Q_{c}$ from the equation because of the complexity of the distribution function. Therefore, the numerical solution of $Q_{c}$ can be calculated by the method of fixed step search in practical application. Property 1 discusses the relationship between retailer's initial order quantity, retail price in the first stage, and profit and parameters $c_{2}$ and $h$ :

Property 1. With other parameters unchanged, when the unit cost $c_{2}$ of the second order increases, the retailer's initial order quantity $Q_{c}$ increases, and the retail price $p_{c}$ and profit $\pi_{c}$ of the first stage decrease monotonously. When the retail price $h$ of the second stage increases, the initial order quantity $Q_{c}$ and profit $\pi_{c}$ increase accordingly.

Proof. If $Q$ is regarded as a function of $c_{2}$, we solve the derivative of both sides of formula (5) on $c_{2}$ and it can be obtained as follows:

$$
\frac{\mathrm{d} Q}{\mathrm{~d} c_{2}}=\frac{1-F_{1}(Q)}{\left(c_{2}-h\right) f_{1}(Q)+(h-s) f(Q)}>0 .
$$

Therefore, the initial order volume of retailers increases monotonously with the value of $c_{2}$. From formula (3), the retail price $p_{c}$ will decrease accordingly.

The same is true as follows:

$$
\frac{\mathrm{d} Q}{\mathrm{~d} h}=\frac{F_{1}(Q)-F(Q)}{\left(c_{2}-h\right) f_{1}(Q)+(h-s) f(Q)}>0 .
$$

Therefore, the initial order volume of retailers increases monotonously with the value of $h$. Substitute (3) into (4) to obtain the following:

$$
\begin{aligned}
\pi_{c}(p, Q)= & {\left[v-(v-h) F_{1}(Q)-c_{2}\right] E\left(X_{1}\right)+\left(c_{2}-c_{1}\right) Q } \\
& -\left(c_{2}-h\right) \int_{0}^{Q} F_{1}(x) \mathrm{d} x-(h-s) \int_{0}^{Q} F(x) \mathrm{d} x .
\end{aligned}
$$

Then, we solve the derivative of formula (8) on $c_{2}$ based on the envelope theorem as follows: 


$$
\frac{\mathrm{d} \pi_{c}}{\mathrm{~d} c_{2}}=-E\left(X_{1}\right)+Q-\int_{0}^{\mathrm{Q}} F_{1}(x) \mathrm{d} x=E\left(\mathrm{Q} \wedge X_{1}\right)-E\left(X_{1}\right) \leq 0 .
$$

Therefore, profits $\pi_{c}$ are decreasing monotonously with respect to $c_{2}$. The same is true as follows:

$$
\begin{aligned}
\frac{\mathrm{d} \pi_{c}}{\mathrm{~d} h} & =F_{1}(Q) E\left(X_{1}\right)+\int_{0}^{\mathrm{Q}} F_{1}(x) \mathrm{d} x-\int_{0}^{\mathrm{Q}} F(x) \mathrm{d} x, \\
& =F_{1}(Q) E\left(X_{1}\right)+\int_{0}^{Q}\left[F_{1}(x) F(x)\right] \mathrm{d} x .
\end{aligned}
$$

Because $F(x)$ and $F_{1}(x)$ are the distribution functions of $X=X_{1}+X_{2}$ and $X_{1}$, respectively, we have $F(x)<F_{1}(x)$ for $\forall x \in[0, Q]$. Therefore, $F_{1}(x)-F(x) \geq 0$. Therefore, from the sign-preserving property of definite integrals, we can see that $\mathrm{d} \pi_{c} / \mathrm{d} h \geq 0$ and the profit $\pi_{c}$ increases monotonously with respect to $h$. Proof is completed.

The conclusion of Property 1 is easy to understand. With the increase in $c_{2}$, retailers have more profit margin in the first order, so they will increase the initial order quantity. The probability that consumers can buy goods in the second stage will also increase with the increase in initial order quantity, which causes retailers to have to reduce retail prices in the first stage. Therefore, under the condition that other parameters remain unchanged, the retailer's profit will decrease; the increase in $h$ means that the same number of goods will get more profit in the second stage, so the retailer's profit will increase. Because $p_{c}=v-(v-h) F_{1}(Q)$, it should be pointed out that the relationship between $p_{c}$ and $h$ is difficult to determine because $v-h$ will decrease with the increase in $h$ and $F_{1}(Q)$ will increase with the increase in order quantity.

In the absence of a second-order opportunity, the retailer's profit function is as follows:

$$
\begin{aligned}
\pi_{1}(p, Q)= & p E\left(X_{1} \wedge Q\right)+h E\left[\left(Q-X_{1}\right)^{+} \wedge X_{2}\right] \\
& +v E\left[\left(Q-X_{1}\right)^{+}-X_{2}\right]^{+}-c_{1} Q .
\end{aligned}
$$

Subscript 1 indicates that there is only one order opportunity. From formulas (2) and (11),

$$
\pi_{c}(p, Q)-\pi_{1}(p, Q)=\left(p-c_{2}\right) E\left(X_{1}-Q\right)^{+} \geq 0 .
$$

Therefore, we could get the following property.

Property 2. For fixed parameters $c_{1}, s, h, v$, and $c_{2}$, the retailer's profit satisfies $\pi_{c}(p, Q) \geq \pi_{1}(p, Q)$.

According to the conclusion of Property 2, the introduction of rapid response mechanism can effectively reduce the negative impact of consumer strategic behavior and improve the profit level of retailers. There are two reasons for the increase in the retailers' profits. First, the initial order quantity will be reduced in the case of two ordering opportunities; that is, the probability that consumers will be able to buy goods during the end-of-season processing period will be correspondingly reduced, which can be effective to reduce the impact of strategic consumers' waiting behaviors on the retailers' profits. Second, because retailers have a second-order opportunity, they can effectively avoid loss of profits caused by insufficient order quantities. Based on this, in the supply chain operations practice of enterprises, if the conditions permit the introduction of a rapid response mechanism, it can improve the efficiency of the supply chain, increase the profit level of the supply chain, and have practical application value.

\section{Initial Order Quantity Commitment}

In the rational expectation equilibrium hypothesis, the retailer's initial order quantity is the retailer's private information, which cannot be directly observed by consumers but is estimated according to the principle of rational expectation equilibrium.

If the retailer discloses the first-order quantity $Q$ to the consumer before the first stage of sales, which is different from the previous rational expectation equilibrium, then the consumers in the first stage do not need to estimate the probability of the goods they can buy after the first stage, and the probability of the goods they can buy is $F_{1}(Q)$. According to the principle of maximizing consumer surplus, consumers make their own purchase timing decision, that is, $\max \left\{v-p,(v-h) F_{1}(Q)\right\}$. While $v-p \geq(v-h) F_{1}(Q)$, they will choose to buy in the first stage, and otherwise, they will wait. Therefore, when the retail price of the first stage satisfies $p \leq v-(v-h) F_{1}(Q)$, consumers will buy goods ahead of time, so in order to maximize profits, the retail price of the first stage should be set as follows: $p_{q}=v-(v-h) F_{1}(Q)$, in which the subscript $q$ denotes the quantity commitment mechanism. Then, the optimal initial order quantity of the retailer should be $Q_{q}^{*}=\arg \pi_{q}(p(Q), Q)$, in which

$$
\begin{aligned}
\pi_{q}(p(Q), Q)= & {\left[v-(v-h) F_{1}(Q)-c_{2}\right] E\left(X_{1}\right) } \\
& +\left(c_{2}-c_{1}\right) Q-\left(c_{2}-h\right) \int_{0}^{Q} F_{1}(x) \mathrm{d} x \\
& -(h-s) \int_{0}^{Q} F(x) \mathrm{d} x .
\end{aligned}
$$

Proposition 3. Retailers have a unique initial order quantity commitment, which maximizes the profits $\pi_{q}(Q)$.

Proof. The derivation of equation (13) on $Q$ can be obtained as follows:

$$
\begin{aligned}
\frac{\mathrm{d} \pi_{q}}{\mathrm{~d} Q}= & -(v-h) E\left(X_{1}\right) f_{1}(Q)-\left(c_{1}-h\right)+\left(c_{2}-h\right) \bar{F}_{1}(Q) \\
& -(h-s) F(Q) .
\end{aligned}
$$

So, the first-order condition is as follows: 


$$
\bar{F}_{1}(Q)\left[\frac{-(v-h) E\left(X_{1}\right) f_{1}(Q)}{\bar{F}_{1}(Q)}-\frac{\left(c_{1}-h\right)}{\bar{F}_{1}(Q)}+\left(c_{2}-h\right)-(h-s) \frac{F(Q)}{\bar{F}_{1}(Q)}\right]=0 .
$$

Set $G(Q)=-(v-h) E\left(X_{1}\right) f_{1}(Q) / \bar{F}_{1}(Q)-\left(c_{1}-h\right) / \bar{F}_{1}$ $(Q)+\left(c_{2}-h\right)-(h-s) F(Q) / \bar{F}_{1}(Q)$.

Because the distribution function of $X_{1}$ satisfies the monotonic incremental failure rate, that is, $f_{1}(Q) / \bar{F}_{1}(Q)$ increase with respect to $Q$ and $\bar{F}_{1}(Q)$ decreases with respect to $Q, F(Q)$ increases with respect to $Q$. Therefore, $G(Q)$ decreases monotonously in $(0,+\infty)$. Because $G(0)=c_{2}-$ $c_{1}>0, G(\infty)=-\infty$, the equation $G(Q)=0$ has a unique root. Moreover, $\bar{F}_{1}(Q)$ is greater than zero in $(0,+\infty)$, equation (14) has a unique root; that is, there is a unique stationary point $Q_{q}^{*}$ for $\pi_{q}(Q)$.

Then, $\pi_{q}^{\prime}(0)=c_{2}-c_{1}>0$ and $\pi_{q}^{\prime}(\infty)=s-c_{1}<0$. Therefore, $\pi_{q}(Q)$ is a quasi-concave function, and $Q_{q}^{*}$ is the maximum point of $\pi_{q}(Q)$. The proof is completed.

This paper compares the relationship between retailer decision variables and profit level under rational expectation equilibrium and initial order commitment mechanism. The conclusions are given by the following property.

Property 3. $Q_{q}^{*}<Q_{c}, p_{q}>p_{c}$ and $\pi_{q}\left(Q_{q}^{*}\right)>\pi_{c}\left(Q_{c}\right)$.

Proof. As can be seen from (14),

$$
\begin{aligned}
\pi_{q}^{\prime}(Q)= & -(v-h) E\left(X_{1}\right) f_{1}(Q)+\left(c_{2}-c_{1}\right) \\
& -\left(c_{2}-h\right) F_{1}(Q)-(h-s) F(Q) .
\end{aligned}
$$

Under the assumption of rational expectation, the retailer's order quantity $Q_{c}$ should satisfy formula (5):

$$
\left(c_{2}-c_{1}\right)-\left(c_{2}-h\right) F_{1}(Q)-(h-s) F(Q)=0 .
$$

Therefore, $\pi_{q}^{\prime}\left(Q_{c}\right)=-(v-h) E\left(X_{1}\right) f_{1}\left(Q_{c}\right)<0$.

According to the nature of the function of $\pi_{q}(Q)$ and $\pi_{q}^{\prime}(Q)$, we get that the profit functions $\pi_{q}(Q)$ and $\pi_{c}(Q)$ have the same function expression under the initial order quantity commitment mechanism and rational expectation equilibrium. So, it can be obtained as shown in Figure 3 that $Q_{q}^{*}<Q_{c}$ and $\pi_{q}\left(Q_{q}^{*}\right)>\pi_{c}\left(Q_{c}\right)$. From the relationship between the initial order quantity and the retail price $p=v-(v-h) F_{1}(Q)$, it can be concluded that $p_{q}>p_{c}$. The proof is completed.

It can be known from Property 3 that the retailer reduces the initial order quantity by committing to the initial order quantity, thereby changing the consumer's expectation; that is, the probability that the product can be purchased at the end of the season clearing period will decrease. At the same time, the retailer increases the retail prices in normal sales period, hedging the loss of the reduction in the number of product sold, which effectively reduces the adverse effects of consumers' strategic behavior. Therefore, retailers can increase their own profit levels by committing to the initial order quantity. In the practice of operations management, many manufacturers have adopted similar marketing methods. For example, manufacturers promise the production quantity of products by launching limited edition products, conveying to consumers that the supply of products exceeds demand, and the expectation that they will not sell at a price reduction in the future prompts consumers competing to buy in the normal sales period. Therefore, it will effectively improve their own profit levels.

However, such a commitment alone is not credible. Because if this commitment is credible, under the initial order quantity commitment mechanism, the retailer can sell product at a relatively high retail price. Then, the retailer "behind the promise" to increase the initial order quantity can increase its own profits. This means that retailers have the urge to deviate from the equilibrium order quantity. The essential reason for the unreliable commitment is that the order quantity and retail price under the initial order quantity commitment mechanism are not the Nash equilibrium solution of the game between the retailer and the consumer. In order to solve the credibility problem of promises, the coordination problem of the supply chain will be studied in the next section.

\section{Supply Chain Coordination}

Under the condition that consumers have strategic behavior, the retailer's profit level in the initial order quantity commitment mechanism is higher than that in the centralized situation, so the goal of supply chain coordination should be defined as the profit level in the initial order quantity commitment mechanism. Next, we discuss the use of twopart pricing contract and revenue-sharing contract to achieve supply chain coordination.

6.1. Two-Part Pricing Contract. Suppose that a two-part pricing contract $(L, w)$ is signed between the manufacturer and the retailer, where $L$ is the fixed fee part, $w$ is the wholesale price of the retailer's first order, and the unit price of the second order is the manufacturer's production cost $c_{2}$ (the reason why the wholesale price of the second order is set as the marginal production cost is that supply chain coordination can be achieved through parameters $L$ and $w$, and the system can be established). Part of the profits lost by the manufacturer can be compensated by a fixed fee. Under this contract, the retailer's profit is as follows (subscript $L$ denotes the value of decision variables and profits under twopart pricing contract, subscript $R$ denotes the retailer, and subscript $M$ denotes the manufacturer):

$$
\begin{aligned}
\pi_{L}^{R}= & p E\left(X_{1} \wedge Q\right)+\left(p-c_{2}\right) E\left(X_{1}-Q\right)^{+} \\
& +h E\left[\left(Q-X_{1}\right)^{+} \wedge X_{2}\right]+s E\left[\left(Q-X_{1}\right)^{+}-X_{2}\right]^{+} \\
& -w Q-L .
\end{aligned}
$$
follows:

The profit of the corresponding manufacturer is as 


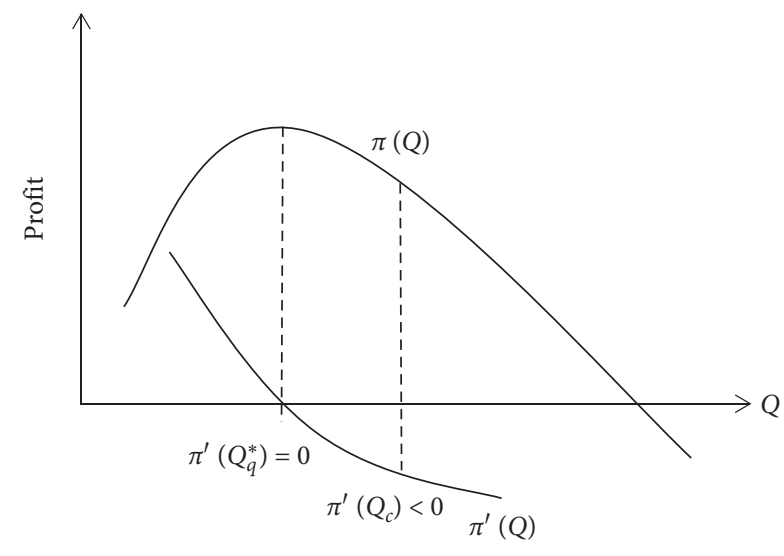

FIGURe 3: Comparisons of centralized SC and initial order quantity under order quantity commitment mechanism.

$$
\pi_{L}^{M}=\left(w-c_{1}\right) Q+L
$$

Proposition 4. When $w=c_{1}+(v-h) E\left(X_{1}\right) f_{1}\left(Q_{q}^{*}\right)$ under the conditions of two-part pricing contract $(L, w)$, it can be concluded that $p_{L}=p_{q}, Q_{L}=Q_{q}^{*}$ and $\pi_{L}=\pi_{L}^{M}+\pi_{L}^{R}=$ $\pi_{q}\left(Q_{q}^{*}\right)$.

Proof. According to equation (18), it can be proved that the retailer's profit under two-part pricing contract is as follows:

$$
\begin{aligned}
\pi_{L}^{R}= & \left(p-c_{2}\right) E\left(X_{1}\right)+\left(c_{2}-w\right) Q-\left(c_{2}-h\right) \int_{0}^{Q} F_{1}(x) \mathrm{d} x \\
& -(h-s) \int_{0}^{Q} F(x) \mathrm{d} x-L .
\end{aligned}
$$

From formula (20), we have the following:

$$
\frac{\partial \pi_{L}^{R}}{\partial \mathrm{Q}}=c_{2}-w-\left(c_{2}-h\right) F_{1}(Q)-(h-s) F(Q)=0 \text {. }
$$

Similar to the proof method in Proposition 1, it is easy to prove that equation (21) has a unique root $Q_{L}$, which is the equilibrium order quantity in the game between retailers and consumers under the assumption of rational expectation equilibrium. Substituting $w=c_{1}+(v-h) E\left(X_{1}\right) f_{1}\left(Q_{q}^{*}\right)$ into formula (21), we obtain the following:

$$
\begin{gathered}
c_{2}-c_{1}-(v-h) E\left(X_{1}\right) f_{1}\left(Q_{q}^{*}\right)-\left(c_{2}-h\right) F_{1}\left(Q_{L}\right) \\
-(h-s) F\left(Q_{L}\right)=0 .
\end{gathered}
$$

As can be seen from Proposition 2, $Q_{q}^{*}$ is the only root of equation (14), so there is

$$
\begin{gathered}
c_{2}-c_{1}-(v-h) E\left(X_{1}\right) f_{1}\left(Q_{q}^{*}\right)-\left(c_{2}-h\right) F_{1}\left(Q_{q}^{*}\right) \\
-(h-s) F\left(Q_{q}^{*}\right)=0 .
\end{gathered}
$$

According to formulas (22) and (23), we get $\left(c_{2}-h\right)\left[F_{1}\left(Q_{L}\right)-F_{1}\left(Q_{q}^{*}\right)\right]+(h-s)\left[F\left(Q_{L}\right)-F\left(Q_{q}^{*}\right)\right]=0$. Because both $F_{1}(Q)$ and $F(Q)$ are strictly monotonic function of $Q,\left(c_{2}-h\right)>0,(h-s)>0, Q_{L}=Q_{q}^{*}$ must be valid. Moreover, since the retail price of the first stage corresponds to the initial order quantity one by one, it is established that $p_{L}=p_{q}$. Finally, the expression of $\pi_{L}$ obtained by adding formulas (18) and (19) is exactly the same to that of $\pi_{q}$, so it holds that $\pi_{L}=\pi_{q}\left(Q_{q}^{*}\right)$ when the order quantity and retail price are equal. Proof is completed.

In traditional supply chain management, the two-part pricing contract generally requires manufacturers to set the wholesale price of a unit product as their unit production cost so as to encourage retailers to order more and make their orders reach the order level of the supply chain under centralized conditions. However, according to the results of Proposition 3, the wholesale price of retailers in two-part pricing contract $(L, w)$ should be fixed $w=c_{1}+$ $(v-h) E\left(X_{1}\right) f_{1}\left(Q_{q}^{*}\right)>c_{1}$, which means that the wholesale price should be higher than the marginal cost of products, which is inconsistent with the conclusion of traditional supply chain management. The reason lies in the influence of consumer's strategic behavior. After considering the consumer's strategic behavior, the profit level of the initial order commitment mechanism is higher than that of the centralized supply chain. Therefore, the manufacturers increase the wholesale price to "force" the retailers to reduce the order quantity, which will improve the performance level of the whole supply chain. Of course, the manufacturers are "willing" to do so.

In traditional supply chain management, the fixed fee part $L$ in the two-part pricing contract is the compensation for the manufacturer's profit and $L$ is always greater than 0 . However, after considering the strategic behavior of consumers, since $w>c_{1}$ is established, manufacturers can profit by selling goods themselves, so $L$ may also play a role of compensation for retailers' profits, that is to say, $L<0$ is also possible. In short, by adjusting the value of $L$, the profit can be arbitrarily distributed among the supply chain members.

Finally, it should be pointed out that in the two-part pricing contract, the profit of the manufacturer is fixed, so it does not need to bear any risks and all risks are borne by the retailer. In the next section, the revenue-sharing contract will be introduced to coordinate the supply chain. The advantage of the revenue-sharing contract is that the risk is also allocated while the revenue is shared.

6.2. Revenue-Sharing Contract. Suppose the manufacturer and the retailer sign a revenue-sharing contract $(w, \lambda)$, where $w$ is the wholesale price of the unit commodity when the retailer first orders to the manufacturer and the manufacturer will share $1-\lambda$ parts of the retailer's total revenue. Under the above revenue-sharing contract, the retailer's profit is (subscript $s$ means revenue-sharing contract) as follows:

$$
\begin{aligned}
\pi_{s}^{R}= & \lambda\left\{p E\left(X_{1} \wedge Q\right)+p E\left(X_{1}-Q\right)^{+}+h E\left[\left(Q-X_{1}\right)^{+} \wedge X_{2}\right]\right. \\
& \left.+s E\left[\left(Q-X_{1}\right)^{+}-X_{2}\right]^{+}\right\}-w Q-c_{2} E\left(X_{1}-Q\right)^{+} .
\end{aligned}
$$

The first bracketed part of the above expression represents the total revenue of the retailer during the whole sales 
process, including the revenue from the sale of the goods in the first stage (including the first order and the second replenishment), the revenue from the sale of the goods in the second stage, and the income from the disposal of the residual value of the goods at the end of the two sales stages. The last two items are the first- and second-order costs, respectively.

The profit of the corresponding manufacturer is as follows:

$$
\begin{aligned}
\pi_{s}^{M}= & (1-\lambda)\left\{p E\left(X_{1} \wedge Q\right)+p E\left(X_{1}-Q\right)^{+}\right. \\
& \left.+h E\left[\left(Q-X_{1}\right)^{+} \wedge X_{2}\right]+s E\left[\left(Q-X_{1}\right)^{+}-X_{2}\right]^{+}\right\} \\
& +\left(w-c_{1}\right) Q .
\end{aligned}
$$

Proposition 5. For any revenue-sharing ratio $0 \leq \lambda<1$, there exists a unique wholesale price $w_{s}$ for the first-order unit. When $w_{s}$ satisfies $w_{s}=c_{2}-\left(c_{2}-\lambda h\right) F_{1}\left(Q_{q}^{*}\right)-\lambda(h-s)$ $F\left(Q_{q}^{*}\right)$, there exists $p_{s}=p_{q}, Q_{s}=Q_{q}^{*}$, and the total profit $\pi_{s}$ of the supply chain at this time is $\pi_{s}=\pi_{s}^{R}+\pi_{s}^{M}=\pi_{q}$.

Proof. According to (24), under the revenue-sharing contract, the retailer's profit function is as follows:

$$
\begin{gathered}
\pi_{s}^{R}=\left(\lambda p-c_{2}\right) E\left(X_{1}\right)+\left(c_{2}-w\right) Q-\left(c_{2}-\lambda h\right) \\
\cdot \int_{0}^{Q} F_{1}(x) \mathrm{d} x-\lambda(h-s) \int_{0}^{Q} F(x) \mathrm{d} x .
\end{gathered}
$$

Therefore, the first-order condition obtained from formula (26) is as follows:

$$
\frac{\partial \pi_{s}^{R}}{\partial Q}=c_{2}-w-\left(c_{2}-\lambda h\right) F_{1}(Q)-\lambda(h-s) F(Q)=0 .
$$

Substituting $w_{s}=c_{2}-\left(c_{2}-\lambda h\right) F_{1}\left(Q_{q}^{*}\right)-\lambda(h-s) F\left(Q_{q}^{*}\right)$ into equation (27), we have the following equation:

$$
\left(c_{2}-\lambda h\right)\left[F_{1}(Q)-F_{1}\left(Q_{q}^{*}\right)\right]+\lambda(h-s)\left[F(Q)-F\left(Q_{q}^{*}\right)\right]=0 .
$$

Since both $F_{1}(Q)$ and $F(Q)$ are strictly monotonic function of $Q$ and $\left(c_{2}-\lambda h\right)>0, \lambda(h-s)>0$, equation (28) has a unique root $Q_{q}^{*}$, that is, $Q_{s}=Q_{q}^{*}$. Similar to the proof process in Proposition 3, it is easy to prove that there is $p_{s}=$ $p_{q}$ and $\pi_{s}=\pi_{s}^{R}+\pi_{s}^{M}=\pi_{q}$. Proof is completed.

According to formula (14), the optimal initial commitment order quantity $Q_{q}^{*}$ of the retailer should satisfy the following equation:

$$
\begin{aligned}
c_{2} & -c_{1}-(v-h) \mathrm{E}\left(X_{1}\right) f_{1}\left(Q_{q}^{*}\right)-\left(c_{2}-h\right) F_{1}\left(Q_{q}^{*}\right) \\
& -(h-s) F\left(Q_{q}^{*}\right)=0 .
\end{aligned}
$$

Therefore, for any proportion of revenue sharing $\lambda$, it holds the following:

$$
\begin{aligned}
w_{s}= & c_{1}+(v-h) \mathrm{E}\left(X_{1}\right) f_{1}\left(Q_{q}^{*}\right)-(h-\lambda h) F_{1}\left(Q_{q}^{*}\right) \\
& +(1-\lambda)(h-s) F\left(Q_{q}^{*}\right) .
\end{aligned}
$$

It could be seen that the wholesale price $w_{s}$ may be greater than $c_{1}$, for example, when $\lambda=1$. This is different from the setting of parameters of revenue-sharing contract in traditional supply chain coordination theory. In traditional supply chain management, $w_{s}$ is usually set equal to or less than the unit marginal cost of production in order to encourage the retailers to order much more. In return, manufacturers will share part of the profits from retailers' sales. In the case that consumers have strategic behavior, manufacturers tend to set the price $w_{s}$ to be greater than $c_{1}$, for the same reason as the two-part pricing contract discussed earlier.

By reasonably setting the parameters of revenue-sharing contract, the coordination of supply chain is also realized, and the profit of manufacturer is closely related to the stochastic demand, so the manufacturer also shares part of the risk of supply chain and makes up for the shortcomings of the two-part pricing contract. The disadvantage of the revenue-sharing contract is that when $\lambda=1$, the manufacturer could still get profits $\left(w-c_{1}\right) Q$, which were monopolized by the manufacturer and could not be distributed among the supply chain members.

\section{Numerical Examples}

Assume that $c_{1}=5, v=15$, and $s=2$. At the same time, it is assumed that the market demand $X_{1}$ of the product in the first stage obeys a normal distribution with mean value $u=$ 75 and standard deviation $\sigma=20$ and the market demand $X_{2}$ in the second stage obeys a normal distribution with mean value $u=25$ and standard deviation $\sigma=15$. Since $X_{1}$ and $X_{2}$ are independent, $X=X_{1}+X_{2} \sim N(100,252)$. When the second unit order price $c_{2}$ increases from 5.5 to 6.5 , the retailer's corresponding equilibrium retail price, initial order quantity, and profit are shown in Figure 4.

It can be seen from Figure 4 that with the increase in the second-order price $c_{2}$, the retail price and profit level of the retailer in the first stage decrease monotonously, and the initial order quantity increases monotonously, which is consistent with the conclusion of Property 1 . With the increase in the second-order cost, the retailer's profit decreased very quickly. When $c_{2}$ increased from 5.5 to 6.5 , it increased by $18.18 \%$, while the profit decreased from 499.9 to 309.9 , a decrease in $38 \%$, which shows that $c_{2}$ has a great impact on retailers' profits. Therefore, in practice, taking effective measures to reduce the cost of rapid response is of great significance for reducing the adverse effects of consumer strategic behavior and improving the performance level of the supply chain.

When the second unit order price $c_{2}$ increases from 5.5 to 6.5 , if the initial order quantity remains unchanged, after the introduction of the quick response mechanism, compared with only one order opportunity, the profit difference is shown in Figure 5. 


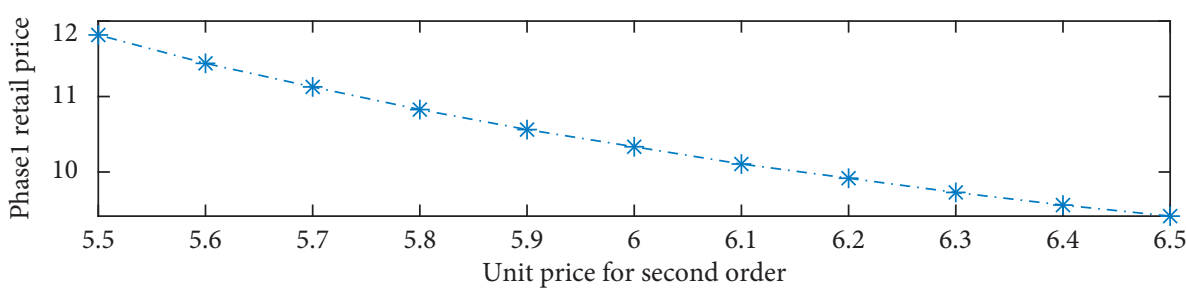

(a)

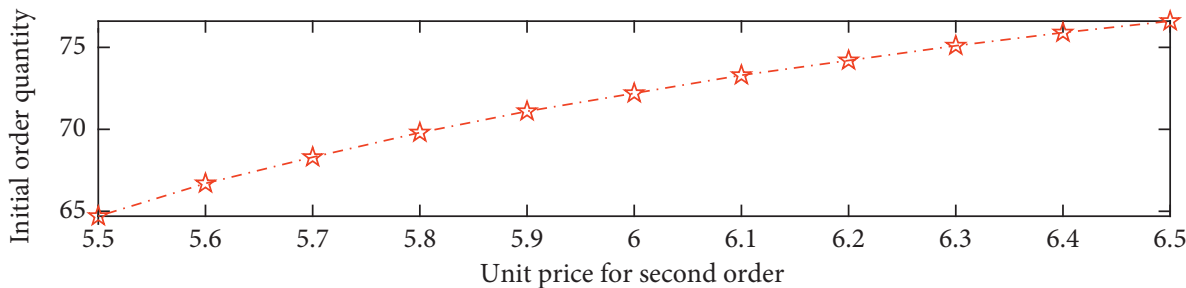

(b)

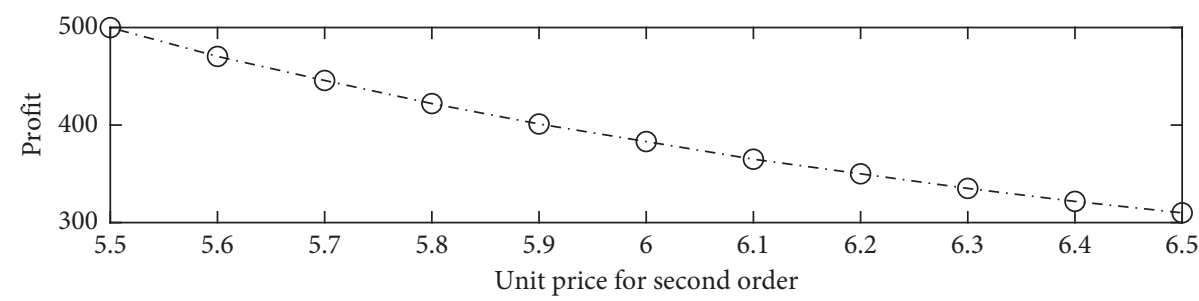

(c)

FIgURE 4: The relationship between the second-order price and the first retail price, order volume, and profit.

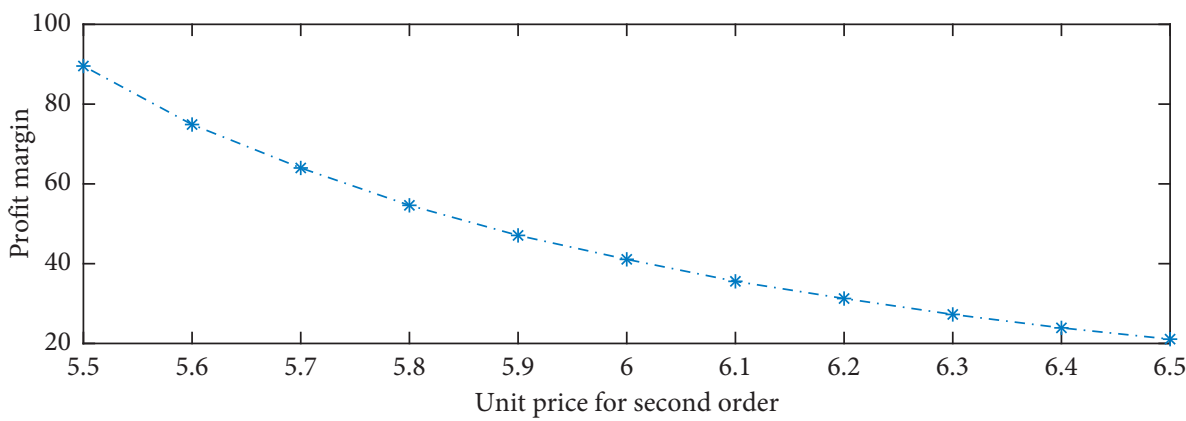

FIGURE 5: Profit difference between quick response mechanism and single order situation.

It can be seen from Figure 5 that the introduction of a rapid response mechanism can always increase the retailer's profit level, which is consistent with the conclusion proved by Property 2, and fully reflect the value of rapid response. We also found that as the unit cost of the second order increases, the profit increase brought about by the rapid response is getting smaller and smaller, because as the cost of the second order increases, the effect that can be obtained through the rapid response decreases.

Suppose $v=15, h=4.5, s=2, X_{1} \sim N(75,202)$, and $X_{2} \sim N(25,152)$, Figure 6 shows when the second unit order price $c_{2}$ increases from 5.5 to 6.5 , the comparison of the rational expectation equilibrium and the initial order quantity commitment mechanism.

It can be seen from Figure 6 that the initial order quantity commitment mechanism has a relatively large decline in the initial order quantity relative to the rational expected equilibrium situation. This is also the most effective means to deal with strategic consumers. It can also be seen that the profit level has been greatly increased after committing to the initial order quantity. For example, when $c_{1}=5, c_{2}=6, v=15, h=4.5, s=2, X_{1} \sim N(75,400), \quad$ and $X_{2} \sim N(25,225)$, under the assumption of rational expectation equilibrium, initial order quantity $Q_{c}=72.2$, retail price of the first stage $p_{c}=10.3345$, and the retailer's profit $\pi_{c}^{R}=383.0678$. Under the initial order quantity commitment mechanism, the initial order quantity $Q_{q}^{*}=27.9$, the retail price of the first stage $p_{c}=14.9027$, and the retailer's profit $\pi_{c}^{R}=695.4776$. The profit has nearly doubled. The result of this example is consistent with Property 3 . At the same time, it can be seen that after introducing the initial order commitment, the probability of consumers being 


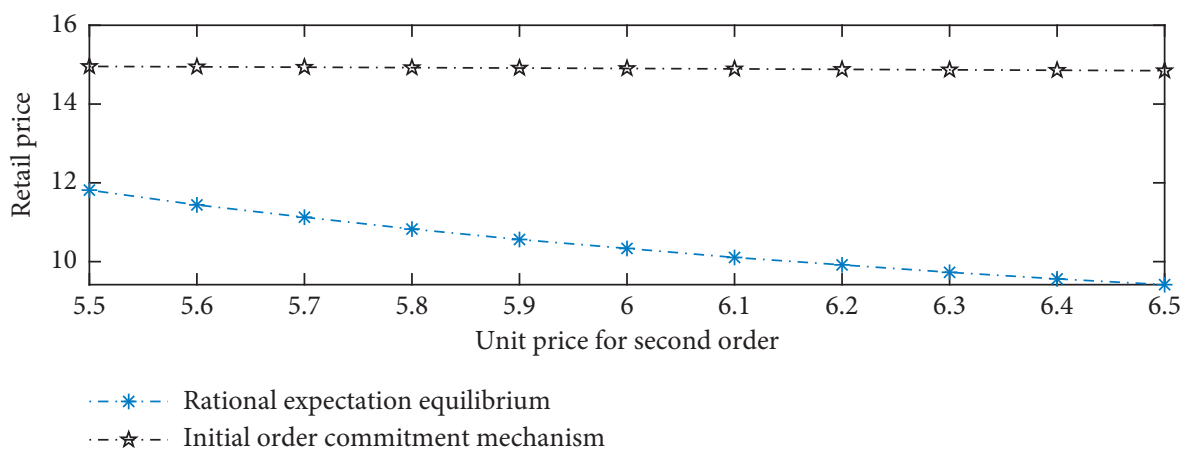

(a)

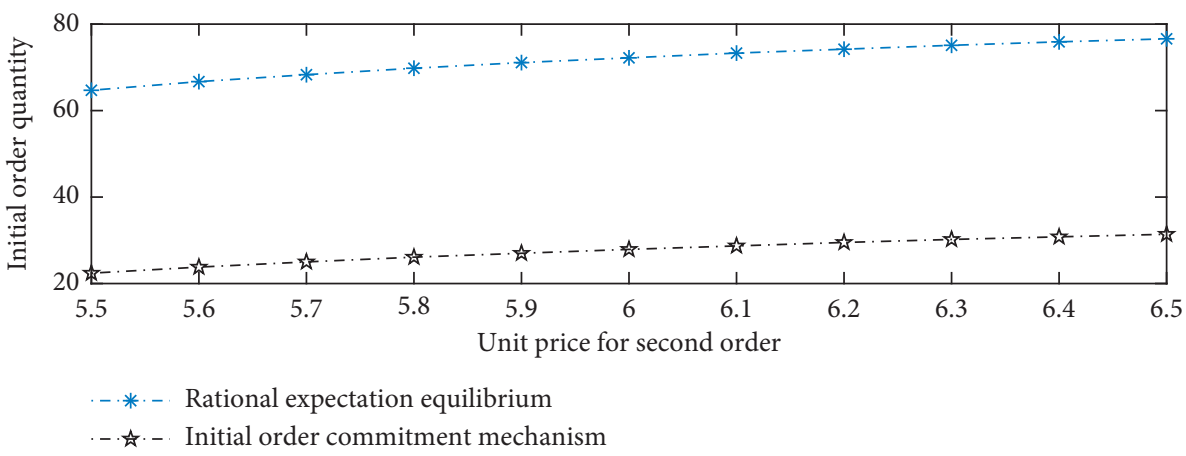

(b)

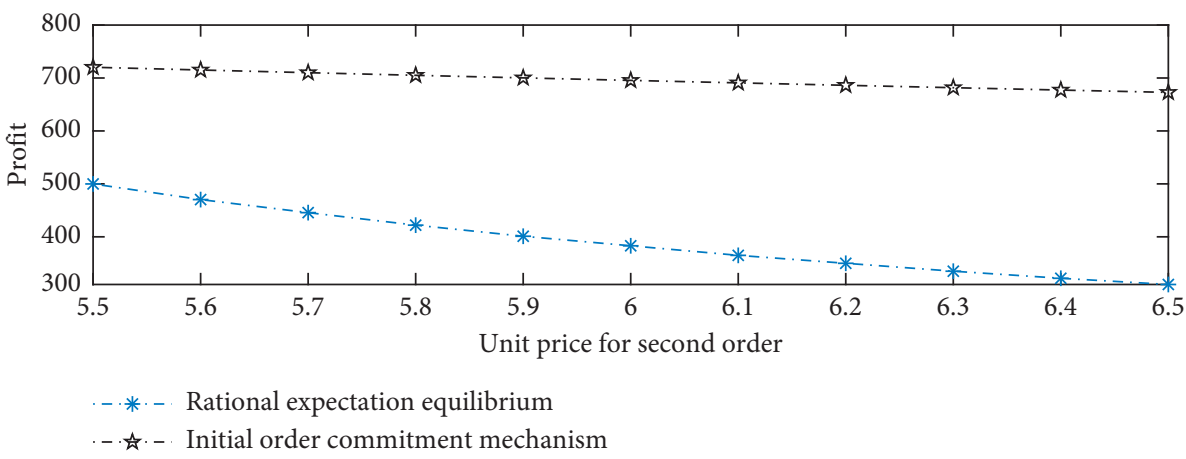

(c)

Figure 6: Comparison of rational expectation equilibrium and initial order quantity commitment mechanism.

able to buy product in the second stage is greatly reduced by reducing the initial order volume, thus "forcing" consumers to buy product in the first stage and greatly increasing the retail price in the first stage. The profit of retailers has been greatly improved, which shows that the effect of the initial order commitment mechanism is obvious.

In two-part pricing contract, if the parameter is set to $w=5.9814$ and $L=0$, then the retailer's profit $\pi_{L}^{R}=$ 668.0978 , the manufacturer's profit $\pi_{L}^{M}=27.3798$, and the total profit of the supply chain $\pi_{L}=695.4776$. The calculation results are consistent with the conclusion given in Proposition 3. The total profit of the supply chain is the same as that of the retailer under the initial order commitment mechanism, which shows that the two-part pricing contract achieves the coordination of the supply chain. If the value of
$L$ is reset, the profit can be distributed arbitrarily between manufacturer and retailer.

Under the revenue-sharing contract, when the revenuesharing ratio $\lambda$ increases from 0 to 1 , the corresponding wholesale price, retailer's profit, and manufacturer's profit change as shown in Figure 7.

As can be seen from Figure 7, with the increase in revenue-sharing ratio $\lambda$, the wholesale price has been rising and is greater than the manufacturer's production cost $c_{1}$; retailer's profits are increasing and manufacturer's profits are decreasing, which is consistent with the theory of revenue-sharing contract. It should be pointed out that no matter what value the $\lambda$ takes, the profit of the manufacturer is greater than 0 . At the end when $\lambda=1$, when the retailer monopolizes all its profits, the manufacturer still gets 27.37 profit, that is to say, the other profit 668.1 except 27.37 can be 


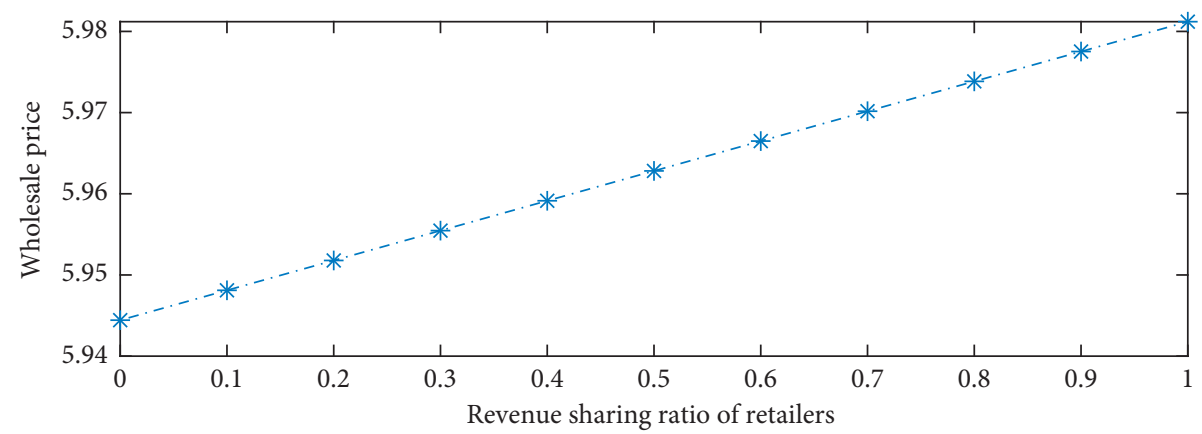

(a)

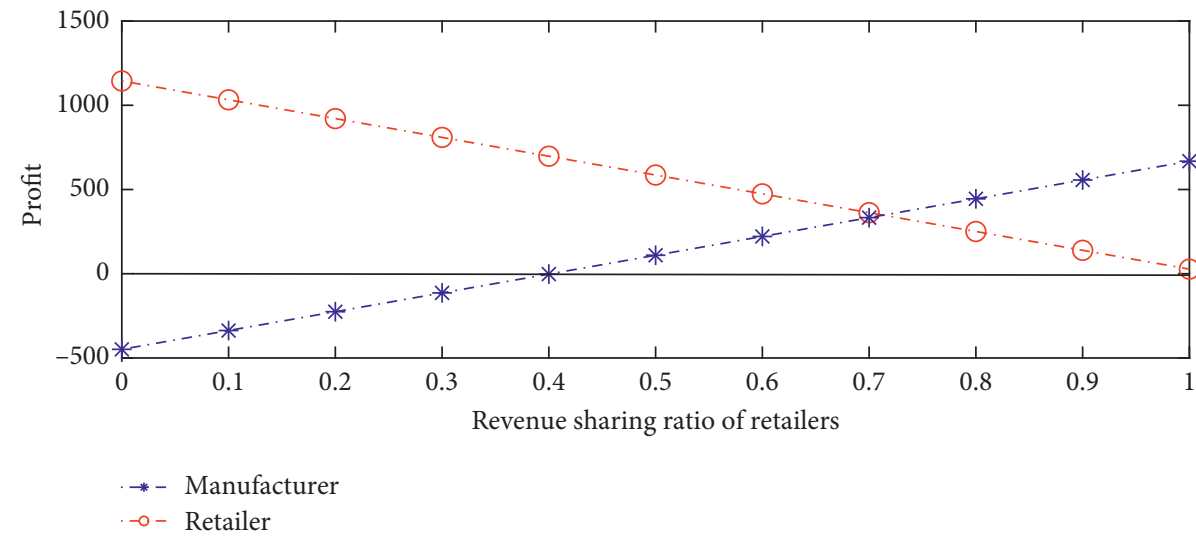

(b)

FIGURE 7: Wholesale price and profit under different revenue-sharing proportions.

arbitrarily allocated among the supply chain members by adjusting the value of the $\lambda$.

\section{Conclusion}

In this paper, the optimal decision-making of supply chain members and the coordination of supply chain in the twoechelon newsvendor model are studied based on consumers' strategic behavior and rapid response mechanism under the condition that retailers are faced with two-stage stochastic demand. Based on the assumption of rational expectation, the equilibrium retail price and initial order quantity of retailers in a centralized supply chain are given, and the influence of the change of relevant parameters on retailers' decision-making is analyzed. The retailer's decision-making under the initial order commitment mechanism and its impact on supply chain profit are discussed. On this basis, aiming at the profit level under the initial order quantity commitment mechanism, two-part pricing contract and revenue-sharing contract are introduced to coordinate the two-echelon supply chain system composed of a single manufacturer and a single retailer. It is proved that both coordination mechanisms can achieve supply chain coordination under reasonable contract parameters. At the same time, the two-part pricing contract can distribute profits arbitrarily among the supply chain members by adjusting the value of the fixed fee. The advantage of the revenuesharing contract is that the manufacturers and retailers share profits while sharing risks. In practical application, enterprise managers can reasonably choose different supply chain coordination mechanisms according to their own needs.

This paper studies the supply chain system of a single manufacturer and a single retailer. It will be a future research direction to analyze the pricing and coordination of supply chain under the competition of multiple manufacturers and retailers. This paper assumes that the retail price of goods in the second stage is an exogenous variable, which can be considered as an endogenous variable in the follow-up study. This paper assumes that all consumers are homogeneous, and the evaluation of goods is the same. When consumers are of different quality, the decision-making problem needs further study [45-48].

\section{Data Availability}

The data used to support the findings of this study are included within the article.

\section{Conflicts of Interest}

The authors declare that they have no conflicts of interest.

\section{Acknowledgments}

This research was supported by the Fundamental Research Funds for the Central Universities (JBK1507105). 


\section{References}

[1] G. H. Anthes, "The price had better be right," Computerworld, vol. 32, no. 21, pp. 65-66, 1998.

[2] C. X. Wang, Q. P. Zhang, and W. Zhang, "Corporate social responsibility, Green supply chain management and firm performance: the moderating role of big-data analytics capability," Research in Transportation Business \& Management, vol. 37, no. 4, Article ID 100557, 2020.

[3] W. Zhang, M. Zhang, W. Zhang, Q. Zhou, and X. Zhang, "What influences the effectiveness of green logistics policies? a grounded theory analysis," Science of the Total Environment, vol. 714, Article ID 136731, 2020.

[4] N. C. Petruzzi and M. Dada, "Pricing and the newsvendor problem: a review with extensions," Operations Research, vol. 47, no. 2, pp. 183-194, 1999.

[5] V. Agrawal and S. Seshadri, "Impact of uncertainty and risk aversion on price and order quantity in the newsvendor problem," Manufacturing \& Service Operations Management, vol. 2, no. 4, pp. 410-423, 2000.

[6] J. D. Dana and N. C. Petruzzi, "Note: the newsvendor model with endogenous demand," Management Science, vol. 47, no. 11, pp. 1488-1497, 2001.

[7] G. J. Kyparisis and C. Koulamas, "The price-setting newsvendor problem with nonnegative linear additive demand," European Journal of Operational Research, vol. 269, no. 2, pp. 695-698, 2018.

[8] M. J. Khouja, "Optimal ordering, discounting, and pricing in the single-period problem," International Journal of Production Economics, vol. 65, no. 2, pp. 201-216, 2000.

[9] S. Ma, Z. Jemai, E. Sahin, and Y. Dallery, "Analysis of the newsboy problem subject to price dependent demand and multiple discounts," Journal of Industrial \& Management Optimization, vol. 14, no. 3, pp. 931-951, 2018.

[10] G. P. Cachon and A. G. Kok, "Implemntation of the newsvendor model with clearance pricing: How to (and how not to) estimate a salvage value," Manufacturing \& Service Operations Management, vol. 9, no. 9, pp. 276-290, 2007.

[11] O. Tang, S. Nurmaya Musa, and J. Li, "Dynamic pricing in the newsvendor problem with yield risks," International Journal of Production Economics, vol. 139, no. 1, pp. 127-134, 2012.

[12] H. K. Alfares and H. H. Elmorra, "The distribution-free newsboy problem: extensions to the shortage penalty case," International Journal of Production Economics, vol. 93, pp. 465-477, 2005.

[13] S. A. Raza, "A distribution free approach to newsvendor problem with pricing," $4 O R$ - A Quarterly Journal of Operations Research, vol. 12, no. 4, pp. 335-358, 2014.

[14] K. Adhikary, J. Roy, and S. Kar, "A distribution-free newsboy problem with fuzzy-random demand," International Journal of Management Science and Engineering Management, vol. 13, no. 3, pp. 200-208, 2018.

[15] H. L. Lee, V. Padmanabhan, T. A. Taylor, and S. Whang, "Price protection in the personal computer industry," Management Science, vol. 46, no. 4, pp. 467-482, 2000.

[16] Q. Zhang, G. Zaccour, J. Zhang, and W. Tang, "Strategic pricing under quality signaling and imitation behaviors in supply chains," Transportation Research Part E: Logistics and Transportation Review, vol. 142, Article ID 102072, 2020.

[17] C. T. Linh and Y. Hong, "Channel coordination through a revenue sharing contract in a two-period newsboy problem," European Journal of Operational Research, vol. 198, no. 3, pp. 822-829, 2009.
[18] S. Hematyar and K. Chaharsooghi, "Coordinating a supply chain with customer returns and two-period newsboy problem using insurance contract," International Journal of Materials, Mechanics and Manufacturing, vol. 2, no. 3, pp. 202-209, 2014.

[19] R. H. Coase, "Durability and monopoly," The Journal of Law and Economics, vol. 15, no. 1, pp. 143-149, 1972.

[20] A. J. Mersereau and D. Zhang, "Markdown pricing with unknown fraction of strategic customers," Manufacturing \& Service Operations Management, vol. 14, no. 3, pp. 355-370, 2012.

[21] Y. Liu and W. L. Cooper, "Optimal dynamic pricing with patient customers," Operations Research, vol. 63, no. 6, pp. 1307-1319, 2015.

[22] D. Yang, E. Qi, and Y. Li, "Quick response and supply chain structure with strategic consumers," Omega, vol. 52, pp. 1-14, 2015.

[23] G. P. Cachon and R. Swinney, "Purchasing, pricing, and quick response in the presence of strategic consumers," Management Science, vol. 55, no. 3, pp. 497-511, 2009.

[24] R. Yin, Y. Aviv, and A. T. Pazgal, "Optimal markdown pricing: implications of inventory display formats in the presence of strategic customers," Management Science, vol. 55, no. 8, pp. 1391-1408, 2019.

[25] G. Lai, L. G. Debo, and K. Sycara, "Buy now and match later: impact of posterior price matching on profit with strategic consumers," Manufacturing \& Service Operations Management, vol. 12, no. 1, pp. 33-55, 2010.

[26] J. Dong and D. D. Wu, "Two-period pricing and quick response with strategic customers," International Journal of Production Economics, vol. 215, pp. 165-173, 2019.

[27] X. Su and F. Zhang, "Strategic customer behavior, commitment, and supply chain performance," Management Science, vol. 54, no. 10, pp. 1759-1773, 2008.

[28] H. Yang, "Impact of discounting and competition on benefit of decentralization with strategic customers," Operations Research Letters, vol. 40, no. 2, pp. 123-127, 2012.

[29] R. Ahmadi, F. Iravani, and H. Mamani, "Supply chain coordination in the presence of gray markets and strategic consumers," Production and Operations Management, vol. 26, no. 2, pp. 252-272, 2017.

[30] S. Hu, Z.-J. Ma, and J.-B. Sheu, "Optimal prices and trade-in rebates for successive-generation products with strategic consumers and limited trade-in duration," Transportation Research Part E: Logistics and Transportation Review, vol. 124, pp. 92-107, 2019.

[31] C. Che, Z. Zhang, X. Zhang, and Y. Chen, "Two-stage pricing decision for low-carbon products based on consumer strategic behaviour," Complexity, vol. 2021, Article ID 6633893, , 2021.

[32] M. Fisher and A. Raman, "Reducing the cost of demand uncertainty through accurate response to early sales," Operations Research, vol. 44, no. 1, pp. 87-99, 1996.

[33] A. V. Iyer and M. E. Bergen, "Quick response in manufacturer-retailer channels," Management Science, vol. 43, no. 4, pp. 559-570, 1997.

[34] M. T. Choi, J. Z. Zhang, and Cheng, "Quick response in supply chains with stochastically risk sensitive retailers," Decision Sciences, vol. 49, no. 5, pp. 781-991, 2018.

[35] H.-L. Chan, B. Shen, and Y. Cai, "Quick response strategy with cleaner technology in a supply chain: coordination and win-win situation analysis," International Journal of Production Research, vol. 56, no. 10, pp. 3397-3408, 2018. 
[36] J. Xu and Y. Duan, "Pricing, ordering, and quick response for online sellers in the presence of consumer disappointment aversion," Transportation Research Part E: Logistics and Transportation Review, vol. 137, Article ID 101925, 2020.

[37] R. Swinney, "Selling to strategic consumers when product value is uncertain: the value of matching supply and demand," Management Science, vol. 57, no. 10, pp. 1737-1751, 2011.

[38] W. Y. Io, "A disneyland dilemma: two-part tariffs for a mickey mouse monopoly," Quarterly Joural of Economics, vol. 85, no. 1, pp. 77-96, 1971.

[39] A. H. L. Lau, H.-S. Lau, and J.-C. Wang, "How a dominant retailer might design a purchase contract for a newsvendortype product with price-sensitive demand," European Journal of Operational Research, vol. 190, no. 2, pp. 443-458, 2008.

[40] J.-C. Wang, A. H.-L. Lau, and H.-S. Lau, "Practical and effective contracts for the dominant retailer of a newsvendor product with price-sensitive demand," International Journal of Production Economics, vol. 138, no. 1, pp. 46-54, 2012.

[41] G. P. Cachon and M. A. Lariviere, "Supply chain coordination with revenue-sharing contracts: strengths and limitations," Management Science, vol. 51, no. 1, pp. 30-44, 2005.

[42] S. Saha, "Supply chain coordination through rebate induced contracts," Transportation Research Part E: Logistics and Transportation Review, vol. 50, pp. 120-137, 2013.

[43] S. Saha and S. K. Goyal, "Supply chain coordination contracts with inventory level and retail price dependent demand," International Journal of Production Economics, vol. 161, pp. 140-152, 2015.

[44] J. F. Muth, "Rational expectations and the theory of price movements," Econometrica, vol. 29, no. 3, pp. 315-335, 1961.

[45] Q. Liu and D. Zhang, "Dynamic pricing competition with strategic customers under vertical product differentiation," Management Science, vol. 59, no. 1, pp. 84-101, 2013.

[46] B. Pal, S. S. Sana, and K. Chaudhuri, "A distribution-free newsvendor problem with nonlinear holding cost," International Journal of Systems Science, vol. 46, no. 7, pp. 1269-1277, 2015.

[47] X. Wang, P. Ma, and Y. Zhang, "Pricing and inventory strategies under quick response with strategic and myopic consumers," International Transactions in Operational Research, vol. 27, no. 3, pp. 1729-1750, 2020.

[48] D. Zhang and W. L. Cooper, "Managing clearance sales in the presence of strategic customers," Production and Operations Management, vol. 17, no. 4, pp. 416-431, 2008. 